\title{
Homer2 and Homer3 modulate RANKL-induced NFATc1 signaling in osteoclastogenesis and bone metabolism
}

\author{
Aran Son1,*, Namju Kang1,2,*, Sue Young Oh1, Ki Woo Kim¹, Shmuel Muallem³, Yu-Mi Yang1 and Dong Min Shin1,2 \\ 'Department of Oral Biology, Yonsei University College of Dentistry, Seoul, Korea \\ 2BK21 PLUS Project, Yonsei University College of Dentistry, Seoul, Korea \\ ${ }^{3}$ Epithelial Signaling and Transport Section, Molecular Physiology and Therapeutics Branch, National Institute of Dental and Craniofacial Research, \\ National Institutes of Health, Bethesda, Maryland, USA
}

Correspondence should be addressed to Y-M Yang or D M Shin: ymyang@yuhs.ac or dmshin@yuhs.ac

*(A Son and N Kang contributed equally to this work)

\begin{abstract}
The receptor activator of nuclear factor-kappa B ligand (RANKL) induces osteoclastogenesis by induction of $\mathrm{Ca}^{2+}$ oscillation, calcineurin activation and translocation into the nucleus of nuclear factor of activated T cells type c1 (NFATC1). Homer proteins are scaffold proteins. They regulate $\mathrm{Ca}^{2+}$ signaling by modulating the activity of multiple $\mathrm{Ca}^{2+}$ signaling proteins. Homers 2 and 3, but not Homer1, also independently affect the interaction between NFATc1 and calcineurin. However, to date, whether and how the Homers are involved in osteoclastogenesis remains unknown. In the present study, we investigated Homer2 and Homer3 roles in $\mathrm{Ca}^{2+}$ signaling and NFATC1 function during osteoclast differentiation. Deletion of Homer2/Homer3 (Homer2/3) markedly decreased the bone density of the tibia, resulting in bone erosion. RANKL-induced osteoclast differentiation is greatly facilitated in Homer2/3 DKO bone marrow-derived monocytes/macrophages (BMMs) due to increased NFATc1 expression and nuclear translocation. However, these findings did not alter RANKL-induced $\mathrm{Ca}^{2+}$ oscillations. Of note, RANKL treatment inhibited Homer proteins interaction with NFATc1, but it was restored by cyclosporine A treatment to inhibit calcineurin. Finally, RANKL treatment of Homer2/3 DKO BMMs significantly increased the formation of multinucleated cells. These findings suggest a novel potent mode of bone homeostasis regulation through osteoclasts differentiation. Specifically, we found that Homer2 and Homer3 regulate NFATC1 function through its interaction with calcineurin to regulate RANKL-induced osteoclastogenesis and bone metabolism.
\end{abstract}

\section{Introduction}

Bone is a dynamic organ. It is constantly renewing through a bone remodeling process, mediated by osteoblastic bone formation and osteoclastic bone resorption. In numerous bone diseases, an imbalance in this process can be found. Examples are autoimmune arthritis, osteoporosis, periodontitis, osteopetrosis and bone tumors (Takayanagi 2007, Zaidi 2007). Multinucleated mature osteoclasts originate from bone marrow-derived 
monocytes/macrophages (BMMs) through two essential factors. One is receptor activator of nuclear factorkappa B ligand (RANKL) secreted by osteoblasts. The other is macrophage-colony-stimulating factor (M-CSF) (Takayanagi 2007). RANK receptor's activation by RANKL leads to oscillations in intracellular $\mathrm{Ca}^{2+}$ concentration $\left(\left[\mathrm{Ca}^{2+}\right]_{\mathrm{i}}\right)$. The latter is linked to the activation of Gq. In turn, Gq generates inositol 1,4,5-triphosphate $\left(\mathrm{IP}_{3}\right)$ to activate the $\mathrm{IP}_{3}$ receptors $\left(\mathrm{IP}_{3} \mathrm{Rs}\right), \mathrm{Ca}^{2+}$ release from the ER and activation of $\mathrm{Ca}^{2+}$ influx from the extracellular space by the Orai channels and transient receptor potential (TRP) channels. Ultimately, as previously reported, this generates an increase in intracellular reactive oxygen species (Yang et al. 2009, 2013, Kim et al. 2010, Son et al. 2012, Park et al. 2013). Subsequently, the RANKLmediated $\left[\mathrm{Ca}^{2+}\right]_{\mathrm{i}}$ oscillations increase NFATc1's nuclear translocation, multinucleated cells' formation and bone resorption (Takayanagi et al. 2002, Yang et al. 2009, Kim et al. 2010).

Members of the NFAT family of transcription factors play a central role in immune responses and in the development of cardiac and skeletal muscles, bone and the nervous system. In these tissues, the NFAT family members are expressed in most cells. The NFAT family consists of five members (NFATc1-5). NFATc1 through NFATc4 are regulated by $\mathrm{Ca}^{2+}$ signaling. Specifically, $\mathrm{Ca}^{2+}$ activates calcineurin by calmodulin. This dephosphorylates NFAT to expose its nuclear import signal (Olson \& Williams 2000, Crabtree \& Olson 2002, Hogan et al. 2003, Takayanagi 2007).

$\mathrm{Ca}^{2+}$ is a universal intracellular messenger that is involved in various cellular functions and processes, such as cell proliferation, differentiation and apoptosis (Bootman et al. 2001, Berridge et al. 2003). Disruption of $\mathrm{Ca}^{2+}$ signaling is one mechanism by which RANKL function, NFATc1 activation and the associated bone metabolism can be altered. An additional less explored mechanism NFAT function's regulation is through their interaction with adapter proteins. As for example SH3 domain-binding protein 2 (3BP2), NFAT-interacting protein (NIP45) and most prominently the Homer proteins (Takayanagi et al. 2002, Foucault et al. 2005, Huang et al. 2008, GuezGuez et al. 2010, Shanmugarajan et al. 2012). The Homer family of scaffolding proteins consists of Homer1, Homer2 and Homer3 and several splice variants. The short Homer1a's gene coding was identified as an immediate early gene transcriptionally upregulated by synaptic activity in neuronal cells
(Brakeman et al. 1997, Xiao et al. 1998, Bottai et al. 2002). Homer1a predominantly consists of the N-terminal Ena/VASP homology 1 (EVH) protein-binding domain. The remaining Homer proteins (i.e., Homer1b/c, Homer2 and Homer3, referred to as 'long Homers') are composed of an EVH domain and a C-terminus. The latter includes a coiled-coil multimerization domain and leucine zipper (Tu et al. 1998, Worley et al. 2007). Of note, the EVH domain binds to several $G$ protein coupled-receptors (GPCRs). Specifically, these are as follows: canonical TRP (TRPC) channels, $\mathrm{IP}_{3} \mathrm{Rs}$, ryanodine receptors (RyRs) and the Shank family of scaffold proteins ( $\mathrm{Tu}$ et al. 1998, 1999, Xiao et al. 1998, Feng et al. 2002, Shin et al. 2003, Yuan et al. 2003). Homer proteins were previously identified as synaptic proteins regulating synaptic activity in neurons. However, earlier studies have reported on the importance of the Homer family in other tissues (Brakeman et al. 1997, Tu et al. 1998, 1999, Xiao et al. 1998). In previous studies, it has been shown that Homer2 modulates the intensity of the GPCRs stimulus. Of note, this is done by regulating the GAP activity of RGS proteins and of PLC $\beta$ in pancreas acinar cells (Shin et al. 2003). In the skeletal muscle, Homer2 enhances the NFATc1-dependent signaling pathway by increasing the release of RyR-dependent $\mathrm{Ca}^{2+}$ during myogenic differentiation (Stiber et al. 2005). It has been demonstrated that Homer3's deletion induces severe autoimmune phenotypes in the lung and liver. Additionally, Homer3's phosphorylation by the $\mathrm{Ca}^{2+} /$ calmodulin-dependent protein kinase (CaMK) II regulates Purkinje cells synaptic activity (Huang et al. 2008, Mizutani et al. 2008). Of note, Homer2 and Homer3 have been shown to regulate $\mathrm{T}$ cell activation through the interaction with NFATc2. Specifically, this is done by competing with calcineurin to bind with NFATc2 (Huang et al. 2008). Additionally, Homer2 identified a co-localization with NFATc1 at the neuromuscular junction. The latter is part of the calcineurin-NFATc1 signaling pathway (Salanova et al. 2011). However, to date, there is a poor understanding of the characteristics of the RANKL-induced NFATc1 signaling pathway during osteoclastogenesis and whether and how it is regulated by Homer proteins.

In the present study, we investigated the role of Homer proteins in the RANKL-induced NFATc1 signaling pathway, osteoclast differentiation and bone metabolism with the use of Homer2 and Homer3 (Homer2/3) double-knockout (DKO) mice. (c) 2019 Society for Endocrinology Published by Bioscientifica Ltd. Printed in Great Britain 


\section{Materials and methods}

\section{Cell culture and reagents}

The Homer2/3 DKO mice were generously provided by Dr Paul F Worley (Johns Hopkins University School of Medicine, Baltimore, MD) (Huang et al. 2008) and all animal care and experimental procedures complied with institutional guidelines and were approved by the Institutional Animal Care and Use Committee (IACUC) in Yonsei University (IACUC approval no. 2014-0067). Primary cultured bone marrow-derived monocytes (BMMs) were maintained in Dulbecco's modified Eagle's medium (DMEM, Invitrogen) and $\alpha$-minimum essential medium ( $\alpha$-MEM) supplemented with 10\% fetal bovine serum (FBS, Invitrogen) and incubated in $5 \% \mathrm{CO}_{2}$. To maintain BMMs, $\alpha$-MEM was supplemented with $30 \mathrm{ng} / \mathrm{mL}$ M-CSF. Receptor activator of RANKL and M-CSF were purchased from KOMA Biotech (Seoul, Korea). Fura-2/AM was purchased from Teflabs (Austin, TX, USA). Pluronic F-127 was obtained from Molecular Probes. Anti-Homer2, anti-Homer3 and anti-NFATc1 antibodies were obtained from Santa Cruz Biotechnology. Anti-actin antibodies were purchased from Sigma-Aldrich.

\section{Preparation of BMMs}

The femur and tibia were isolated from 4 6-week-old mice as described previously (Kim et al. 2010). All cells derived from bone marrow of femur and tibia were collected and cultured in $\alpha$-MEM medium containing 10\% FBS and $30 \mathrm{ng} / \mathrm{mL} \mathrm{M}$-CSF. The following day, non-adherent cells in media were collected and seeded on adequate plates and treated with M-CSF (30 ng/mL). After 2 days nonadherent cells were washed out and adherent cells were used as BMMs.

\section{Analysis of bone density and skeletal morphology}

Tibias and femora were isolated from 6-week-old WT and Homer2/3 DKO mice. To exclude differences caused by threshold resolution set-up, samples from WT and Homer2/3 DKO were set in one soft X-ray apparatus. Bone density was measured with a 3D $\mu \mathrm{CT}$ (SkyScan-1076 high resolution in vivo $\mu \mathrm{CT}$ system; SkyScan, Aartselaar, Belgium) and analyzed with CTAn and Cone beam reconstruction software. Histological examination was performed as described elsewhere (Mayingi et al. 2007). Dynamic histomorphometric method was as described before (Kim et al. 2010). Briefly, 4-week-old male mice were injected twice with calcein $(15 \mathrm{mg} / \mathrm{kg}$ intraperitoneally) 2 days apart. The animals were killed on day 4, and undecalcified bones were embedded in methylmethacrylate. Longitudinal sections $(10 \mu \mathrm{m}$ thickness) of the tibias were prepared, and new bone formation was assessed by confocal microscopy (model LSM 510; Carl Zeiss) by capturing images of calcein green.

\section{$\left[\mathrm{Ca}^{2+}\right]_{\mathrm{i}}$ measurement}

The cells were seeded on cover glass in a $35 \mathrm{~mm}$ dishes $\left(5 \times 10^{4}\right.$ cells/coverslip) and stimulated with RANKL $(50 \mathrm{ng} / \mathrm{mL})$ for the indicated times. The cells were loaded with $5 \mu \mathrm{M}$ Fura-2/AM and 0.05\% Pluronic F-127 for $30 \mathrm{~min}$ in physiological salt solution $(140 \mathrm{mM} \mathrm{NaCl}, 5 \mathrm{mM} \mathrm{KCl}$, $1 \mathrm{mM} \mathrm{MgCl}_{2}, 1 \mathrm{mM} \mathrm{CaCl} 2,10 \mathrm{mM}$ HEPES, $10 \mathrm{mM}$ glucose, 310 mosmol, pH 7.4). Fura-2 fluorescence intensity was measured using excitation wavelengths of 340 and $380 \mathrm{~nm}$, and emitted fluorescence $510 \mathrm{~nm}\left(\mathrm{ratio}=\mathrm{F}_{340} / \mathrm{F}_{380}\right)$ was collected and monitored at 2 s intervals using a CCD camera (Universal Imaging Co., Downingtown, PA, USA) as described previously (Yang et al. 2009). Images were digitized and analyzed by MetaFlour software (Universal Imaging).

\section{Western blot}

Whole-cell lysates were prepared using RIPA lysis buffer (20 mM Tris, $\mathrm{pH} 7.4,250 \mathrm{mM} \mathrm{NaCl}, 2 \mathrm{mM}$ EDTA, $\mathrm{pH}$ 8.0, $0.1 \%$ Triton $\mathrm{X}-100,0.01 \mathrm{mg} / \mathrm{mL}$ aprotinin, $5 \mu \mathrm{g} / \mathrm{mL}$ leupeptin, $0.4 \mathrm{mM} \mathrm{PMSF}$ and $4 \mathrm{mM} \mathrm{NaVO}_{4}$ ) and spun at $13,000 \mathrm{~g}$ for $10 \mathrm{~min}$ to remove insoluble material. Proteins (50 100 $\mu \mathrm{g} /$ well) were subjected to 6 8\% SDS-PAGE and were separated by size. Proteins were electro-transferred to a nitrocellulose membrane, blocked with $6 \%$ skimmed milk and probed with Abs against NFATc1 (1:1000) and actin (1:2000). Thereafter, blots were washed, exposed to horseradish peroxidase-conjugated secondary antibodies for $1 \mathrm{~h}$ and finally detected by chemiluminescence (Amersham Pharmacia Biotech).

\section{Immunoprecipitation}

The immunoprecipitation was as before (Shin et al. 2003, Yang et al. 2014) with several modifications. In brief, microsomes were prepared from BMMs harvested from WT mice in a buffer containing $20 \mathrm{mM}$ Mops (pH 6.7 with $\mathrm{KOH}), 250 \mathrm{mM}$ sucrose, $1 \mathrm{mM}$ EDTA, $1 \mathrm{mM} \mathrm{MgCl}_{2}$, $10 \mathrm{mM}$ benzamidine and $0.2 \mathrm{mM}$ PMSF. The homogenates were centrifuged at $400 \mathrm{~g}$ for $10 \mathrm{~min}$ and the supernatants 
were collected and re-centrifuged at $900 \boldsymbol{g}$ for $10 \mathrm{~min}$ at $4^{\circ} \mathrm{C}$. Microsomes were lysed in a buffer containing $50 \mathrm{mM}$ Tris (pH 6.8 with $\mathrm{HCl}$ ), $150 \mathrm{mM} \mathrm{NaCl}, 3 \mathrm{mM}$ EDTA, $2 \mathrm{mM}$ EGTA and $0.5 \%$ Triton X-100 supplemented with protease inhibitors. The lysates were cleared by centrifugation at $14,000 \mathrm{~g}$ for $15 \mathrm{~min}$. About $150 \mu \mathrm{L}$ of the extract $(300 \mu \mathrm{g}$ of protein/sample) was incubated for 10 days in a buffer containing $50 \mathrm{mM}$ Tris $(\mathrm{pH} 6.8$ with $\mathrm{HCl}), 150 \mathrm{mM}$ $\mathrm{NaCl}, 3 \mathrm{mM}$ EDTA, $2 \mathrm{mM}$ EGTA. Protein A/G-agarose (Thermo Fisher Scientific) was added to each mixture, and rocking was continued overnight at $4^{\circ} \mathrm{C}$. Protein A/G-agarose was pelleted at $1000 \boldsymbol{g}$ for $10 \mathrm{~s}$ and the beads were quickly washed with cold phosphate buffered saline (PBS). The immunoprecipitated proteins were separated by SDS-PAGE and probed with anti-Homer3 (1:1000) by overnight incubation at $4^{\circ} \mathrm{C}$. To avoid protein degradation by digestive enzymes, immunoprecipitation was initiated immediately after completion of microsomal preparation.

\section{Immunocytochemistry}

Cells were seeded on coverslips $(12 \mathrm{~mm})$ and treated for 4 days with $50 \mathrm{ng} / \mathrm{mL}$ RANKL. After fixation in $4 \%$ paraformaldehyde (PFA) for $5 \mathrm{~min}$, cells were sequentially incubated in blocking solution $(0.1 \%$ gelatin, $1 \%$ BSA, $0.01 \%$ sodium azide, $5 \%$ goat serum) for $1 \mathrm{~h}$, overnight in blocking solution containing Abs against NFATc1 (1:100), and finally were treated with Alexa 488-labeled anti-mouse IgG antibody (Molecular Probes) in blocking solution for $1 \mathrm{~h}$. Nuclei was separately stained with TO-PRO3. F-actin was visualized with Alexa Fluor 488-Phalloidin.

\section{TRAP stain assay}

BMMs were seeded in 96-well plates at a density of $3 \times 10^{5}$ cells per well and pretreated with the indicated compounds. Cells were then stimulated with $50 \mathrm{ng} / \mathrm{mL}$ RANKL. After 4 days, a TRAP stain assay was performed to evaluate the cell differentiation rate. TRAP staining was performed as described previously (Yang et al. 2009). Cells were fixed with 10\% PFA and with ethanol/acetone (1:1) solution. $100 \mu \mathrm{L}$ of TRAP staining solution were added to each well and stained for $5 \mathrm{~min}$. TRAP-positive multinucleated cells (containing $\geq 3$ nuclei) were then counted.

\section{Measurement of bone resorption rate (pit assay)}

Collected BMMs were seeded on Osteo assay plates (Corning) coated with a proprietary hydroxyapatite mineral surface. Following stimulation
(50 ng/mL M-CSF and sRANKL) of the BMMs for 6 days, the plates were washed with sodium hypochlorite solution for $1 \mathrm{~h}$ at room temperature. Pits formed on the surface of the hydroxyapatite mineral were imaged and calculated using MetaMorph software (Molecular Devices).

\section{Alkaline phosphatase activity and Alizarin red S staining}

After bone marrow stromal cells (BMSCs) were transduced, they were seeded into 48 -well plates at a density of $5 \times 10^{5}$ cells per well. After osteogenic induction for indicated days, cells were rinsed two times with PBS. ALP and ARS (both from Sigma-Aldrich) were added into cells for the staining during $30 \mathrm{~min}$. Staining agent was discarded and cells were rinsed 4-5 times with water and air-dried. Images of each sample were acquired using a CCD camera. To quantify matrix mineralization, cells were incubated in $100 \mathrm{mM}$ cetylpyridinium chloride for ARS and alkaline phosphatase yellow for ALP. The concentration of ARS was measured using a microplate spectrophotometer at a $562 \mathrm{~nm}$ wavelength and ALP activity was measured at the wavelength of $405 \mathrm{~nm}$.

\section{Statistical analysis}

All data were expressed as the mean \pm s.E.M. Statistical significance was determined by using a paired Student's $t$-test. Statistical significance was set at $P<0.05$ level.

\section{Results}

\section{Decreased bone density in Homer2/3 DKO mice}

Homer proteins have been shown to be regulators of $\mathrm{Ca}^{2+}$ signaling pathways and direct regulators of NFAT activation in T cells (Huang et al. 2008). In the present study, we examined whether the deletion of Homer proteins affects bone metabolism through bone remodeling. The tibias of WT and Homer2/3 DKO mice were dissected. Subsequently, we evaluated bone density by microradiographic and histological analyses. The tibias' bone density (bone volume/total volume, BV/TV) and the trabecular bone's thickness from Homer2/3 DKO mice were significantly reduced $(\sim 44.5$ and $\sim 38.5 \%$, respectively) vs WT (Fig. 1A). Histologically, Homer $2 / 3$ DKO mice exhibited an extensive resorption of trabecular bone below the growth plate and epiphysis of the tibia. Additionally, Homer2/3 DKO mice had a significantly 


\begin{tabular}{l|l|l|r|r|}
$\begin{array}{l}\text { Journal of } \\
\text { Endocrinology }\end{array}$ & A Son, N Kang et al. & $\begin{array}{l}\text { Roles of Homer2/3 in } \\
\text { osteoclastogenesis }\end{array}$ & $\mathbf{2 4 2 : 3}$ & $\mathbf{2 4 5}$ \\
\hline
\end{tabular}

A
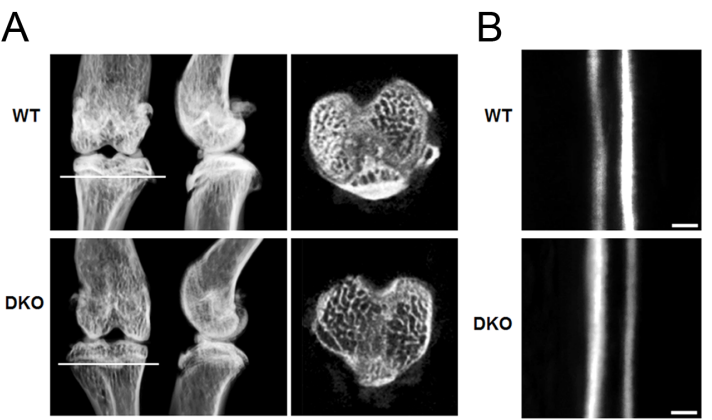

C

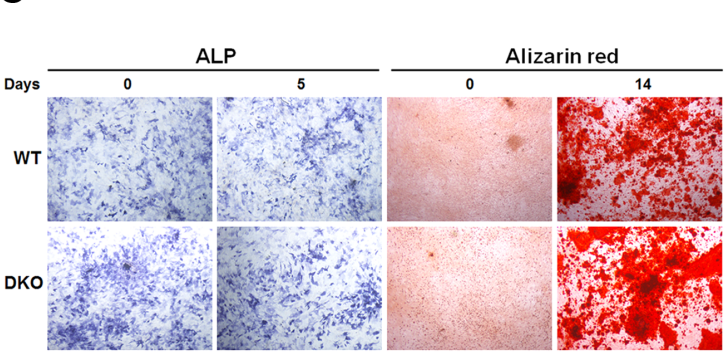

D
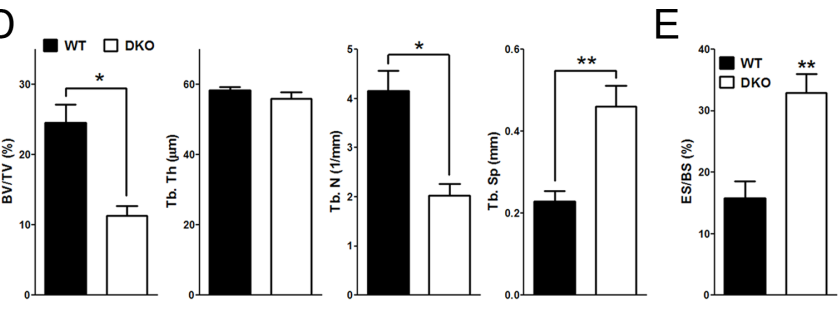

F
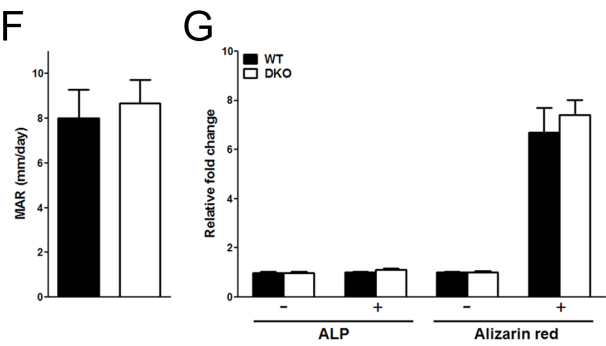

\section{Figure 1}

Decreased bone density in Homer2/3 DKO mice. (A) Microradiographic analyses of tibias in WT and Homer2/3 DKO mice. Note that in Homer2/3 DKO tibias, trabecular and cortical bone mass decreased (6 weeks). (B) Representative calcein-labeled sections of proximal tibias in WT and Homer2/3 DKO mice (scale bar, $20 \mu \mathrm{m}$ ). (C) Alkaline phosphatase (ALP) Alizarin red S (ARS) staining ( $n=4)$ ). (D) $\mu C T$ data of proximal femur obtained from WT and Homer2/3 DKO mice. Each parameter, including BV/TV, Tb. Th, Tb. N and Tb. Sp were calculated and presented. (E) Histomorphometric parameters. The percentage of eroded surface (ES) on bone surface (BS) increased in Homer2/3 DKO mice (left, $n=3$ ). (F) We observed no clear difference in mineral apposition rate (MAR) between Homer2/3 DKO and WT mice (middle, $n=7$ ). (G) Following ALP activity and ARS staining, we found no difference in osteoblastogenesis between WT and DKO mice (right, $n=4$ ). Data were normalized to bone volume in WT mice and expressed as means \pm S.E.M. $* P<0.05$, $* * P<0.01$ compared with WT.

increased erosion surface on bone by $\sim 1.08$-fold (eroded surface/bone surface, ES/BS) (Fig. 1D).

Next, we aimed at analyzing the impact of Homer $2 / 3$ deletion on bone formation rates. To this end, we performed dynamic histomorphometric measurements on 4-week-old mice double-labeled with sequential doses of calcein. We did not observe a clear difference in bone-formation rate and mineral apposition rate (MAR) between Homer2/3 DKO and WT mice (Fig. 1B and E). Of note, the results for osteoblastogenesis by alkaline phosphatase (ALP) activity and alizarin red S (ARS) staining showed no difference between DKO and WT mice (Fig. 1C and F).

\section{Homer2/3 deletion does not affect RANKL-induced $\left[\mathrm{Ca}^{2+}\right]_{\mathrm{i}}$ oscillation}

It has been previously shown that RANKL-induced $\left[\mathrm{Ca}^{2+}\right]_{\mathrm{i}}$ oscillations are essential for osteoclast differentiation (Takayanagi et al. 2002). As a consequence, we analyzed $\mathrm{Ca}^{2+}$ signaling in RANKL-treated BMMs obtained from WT and Homer2/3 DKO mice. We initiated $\left[\mathrm{Ca}^{2+}\right]_{\mathrm{i}}$ oscillations after $24 \mathrm{~h}$ of RANKL treatment in both WT and Homer2/3 DKO BMMs (Fig. 2A and B).
We observed that the number of responding cells and the frequency of $\left[\mathrm{Ca}^{2+}\right]_{\mathrm{i}}$ oscillations were not altered by the deletion of Homer2/3 (Fig. 2B and C).

\section{Key role of Homer2/3 proteins in RANKL-induced NFATc1 expression and osteoclastogenesis}

It has been previously shown that Homer2 and Homer3 interfere with the interaction of NFAT with calcineurin (Huang et al. 2008, Salanova et al. 2011). Therefore, we examined the effects of Homer2/3 proteins on NFATc1 expression and translocation into the nucleus in BMMs after RANKL treatment. We observed that the expression of Homer proteins was not affected by RANKL's treatment of WT BMMs (Fig. 3A). RANKL induced a transient and moderate increase in NFATc1 protein levels after $12 \mathrm{~h}$ of treatment. Subsequently, it caused a sustained upregulation, which persisted for several days in WT and Homer2/3 DKO BMMs (Fig. 3B). The RANKLinduced upregulation of NFATc1 in Homer2/3 DKO cells was significantly higher after 48 and $72 \mathrm{~h}$ vs WT BMMs (Fig. 3C). Of note, we found that NFATc1 translocation into the nucleus was markedly increased in Homer2/3 DKO BMMs (Fig. 3D and E). 
A
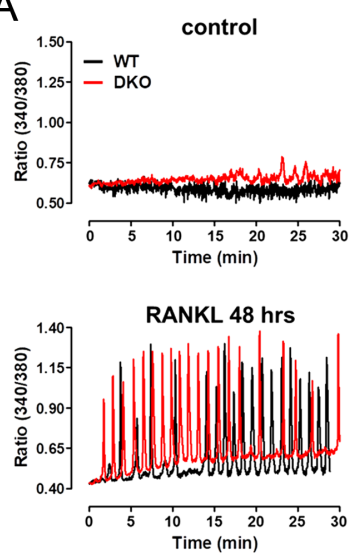

RANKL 24 hrs

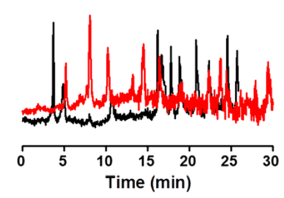

RANKL 72 hrs

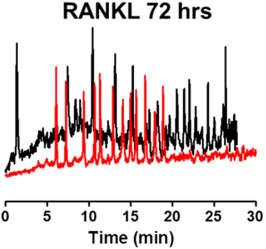

B

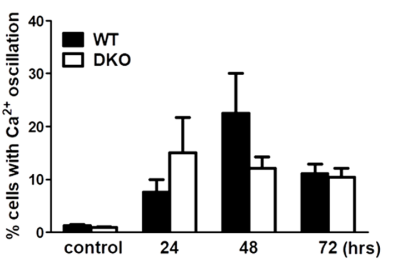

C

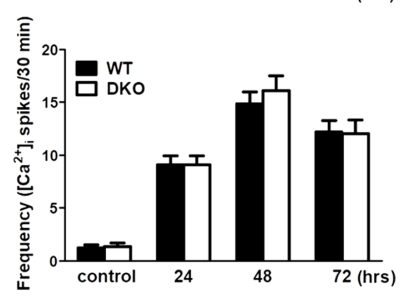

Figure 2

RANKL-induced $\left[\mathrm{Ca}^{2+}\right]_{i}$ oscillations in WT and Homer2/3 DKO BMMs. (A) Oscillatory change in $\left[\mathrm{Ca}^{2+}\right]_{\mathrm{i}}$ in WT and Homer2/3 DKO BMMs before and after RANKL treatment. (B) Quantitative analysis of the number of cells with $\left[\mathrm{Ca}^{2+}\right]_{i}$ oscillation induced by RANKL in WT and Homer2/3 DKO BMMs $(n=3)$. (C) Oscillation frequency at 24 , 48 and $72 \mathrm{~h}$. Data are expressed as mean \pm S.E.M.
Earlier studies have reported that $\mathrm{T}$ cells and skeletal muscle Homer proteins interact with and sequester NFAT in the cytosol (Huang et al. 2008, Salanova et al. 2011). We aimed at examining the interaction of Homer proteins with NFATc1 in BMMs and determining if it is affected by the induction of osteoclastogenesis. As a consequence, we examined both whether Homer proteins selectively bind NFATc1 and RANKL stimulation affects the interaction in WT and Homer2/3 DKO BMMs. Figure 3F shows the co-immunoprecipitation with NFATc1 of Homer2 and Homer3 prior to RANKL stimulation. Importantly, RANKL stimulation significantly reduced the interaction aimed at dissociating the NFATc1/Homers complexes. Of note, following treatment with the specific calcineurin inhibitor cyclosporine A, Homer proteins and NFATc1's interaction were restored and complex formation was enhanced.

Next, we aimed at confirming the role of Homer proteins in RANKL-mediated osteoclasts differentiation.

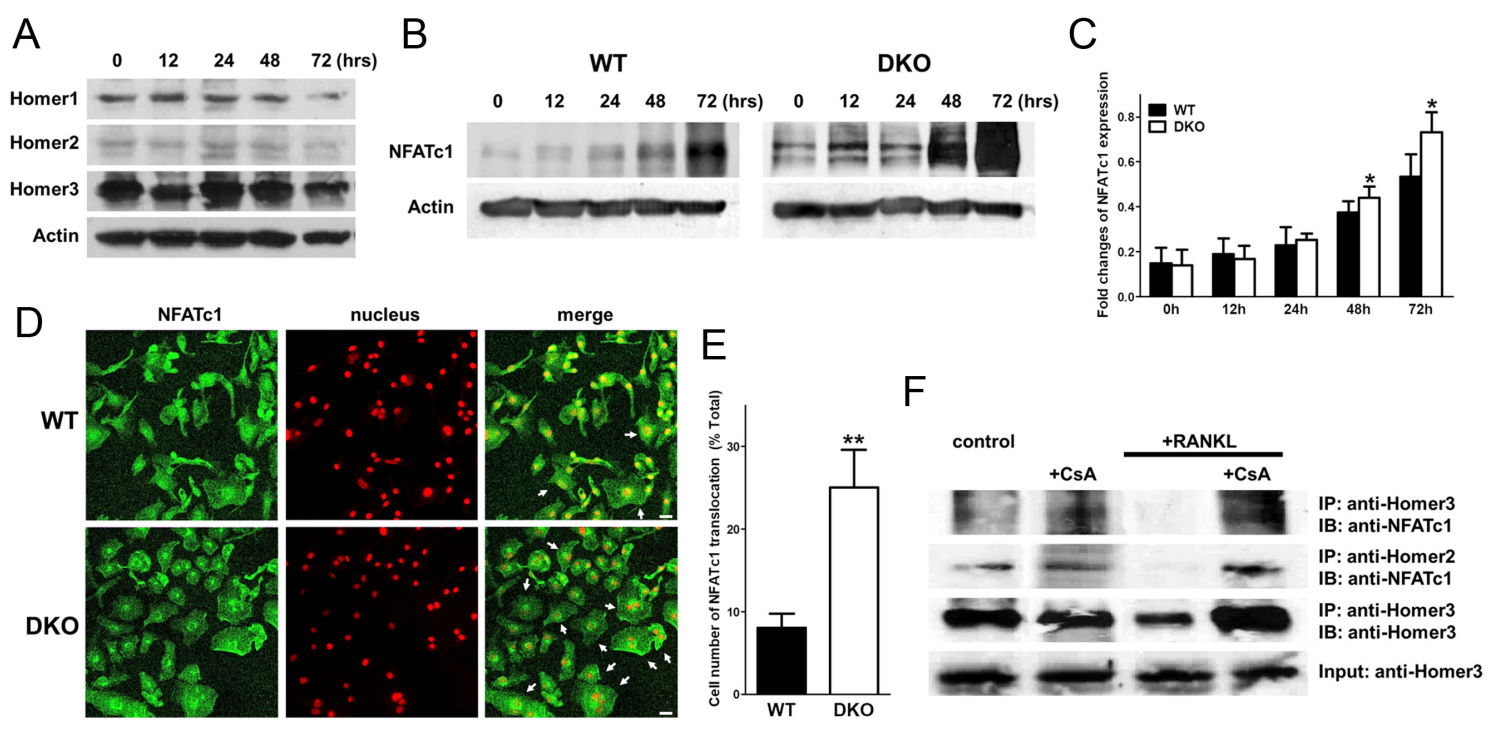

\section{Figure 3}

RANKL-induced NFATc1 expression and translocation depend on the interaction of Homer proteins with NFATc1. (A) Expression levels of Homer proteins $(45 \mathrm{kDa})$ and $\beta$-actin $(42 \mathrm{kDa}$ ) in WT BMMs after RANKL stimulation. (B) Expression level of NFATc1 (approximately $90 \sim 110 \mathrm{kDa}$ ) and $\beta$-actin in WT and Homer2/3 DKO BMMs following RANKL stimulation. (C) Mean NFATC1 expression levels in WT and Homer2/3 DKO BMMs. We analyzed by densitometry the expression levels in experiments similar to those in B. Specifically, we observed that NFATc1's expression levels between 48 and $72 \mathrm{~h}$ were significantly increased in Homer2/3 DKO cells $(n=6)$. Data were normalized to expression level in cells from WT mice and expressed as the mean \pm s.E.M. (D) NFATc1 protein's immunostaining in WT and Homer2/3 DKO BMMs post $72 \mathrm{~h}$ RANKL stimulation. Of note, NFATc1's nuclear translocation was significantly higher in Homer2/3 DKO vs WT BMMs. Arrows indicate nuclear localized NFATc1. TO-PRO3 counterstaining was performed on the nuclei (scale bar, $20 \mu \mathrm{m}$ ). (E) Quantification of cell number with nuclear NFATc1. Homer2/3 DKO cells had a significant increase in NFATc1 translocation $(n=7)$. (F) Homer proteins and NFATc1 co-immunoprecipitation in cell lysates prepared from WT BMMs before and after 24-h RANKL stimulation. A reduced interaction of NFATC1 with Homer3 and Homer2 was found following RANKL stimulation. As a control, inhibition of calcineurin with cyclosporine A (CSA, $0.01 \mu \mathrm{g} / \mathrm{mL}$ ) to inhibit NFATc1 dephosphorylation increased NFATc1's interaction with Homer3 and Homer2 and reversed RANKL stimulation's effect. $\star P<0.05$ and $* * P<0.01$ compared with WT. 
To this end, we used TRAP staining with the goal of determining the difference between the morphology of differentiated Homer2/3 DKO osteoclasts and that of WT cells. We found that a 4-day RANKL stimulation increased the formation of TRAP+ MNCs such that the increase was higher in cells from Homer2/3 DKO. Additionally, the morphological features characteristic of osteoclast differentiation (i.e., the number of nuclei and area of MNCs) were enhanced in the RANKL-induced Homer2/3 DKO BMMs vs WT BMMs (Fig. 4A). We then examined Homer2/3's effect on osteoclast function by performing pit formation and actin ring formation assays. Osteoclasts were generated on a bone resorption assay plate. We observed that the percentage of bone resorption area increased in the RANKL-induced Homer2/3 DKO cells. Additionally, the actin staining results demonstrated that area of MNCs is higher in Homer2/3 DKO cells (Fig. 4B and C).

\section{Discussion}

In the present study, we report a novel interaction between Homer2/3 and NFATc1 for the regulation of osteoclastogenesis and bone metabolism. Our study demonstrates that inhibition of Homer2/3 expression strongly facilitates osteoclastogenesis. Homer2/3 DKO mice had an osteoporotic phenotype. The latter was caused by increased osteoclast differentiation with a wider bone erosion surface, independent of the rate of osteoblastic bone formation. We traced the aberrant bone metabolism to reduced Homer2/3 expression responsible for inducing NFATc1 with a sustained increase in its levels several days from RANKL treatment and a marked increase in its nuclear localization. These findings suggest that Homer2 and Homer3 are key regulators of RANKL-mediated osteoclastogenesis by linking RANKL-induced NFATc1 activation to the last stages of osteoclast differentiation.
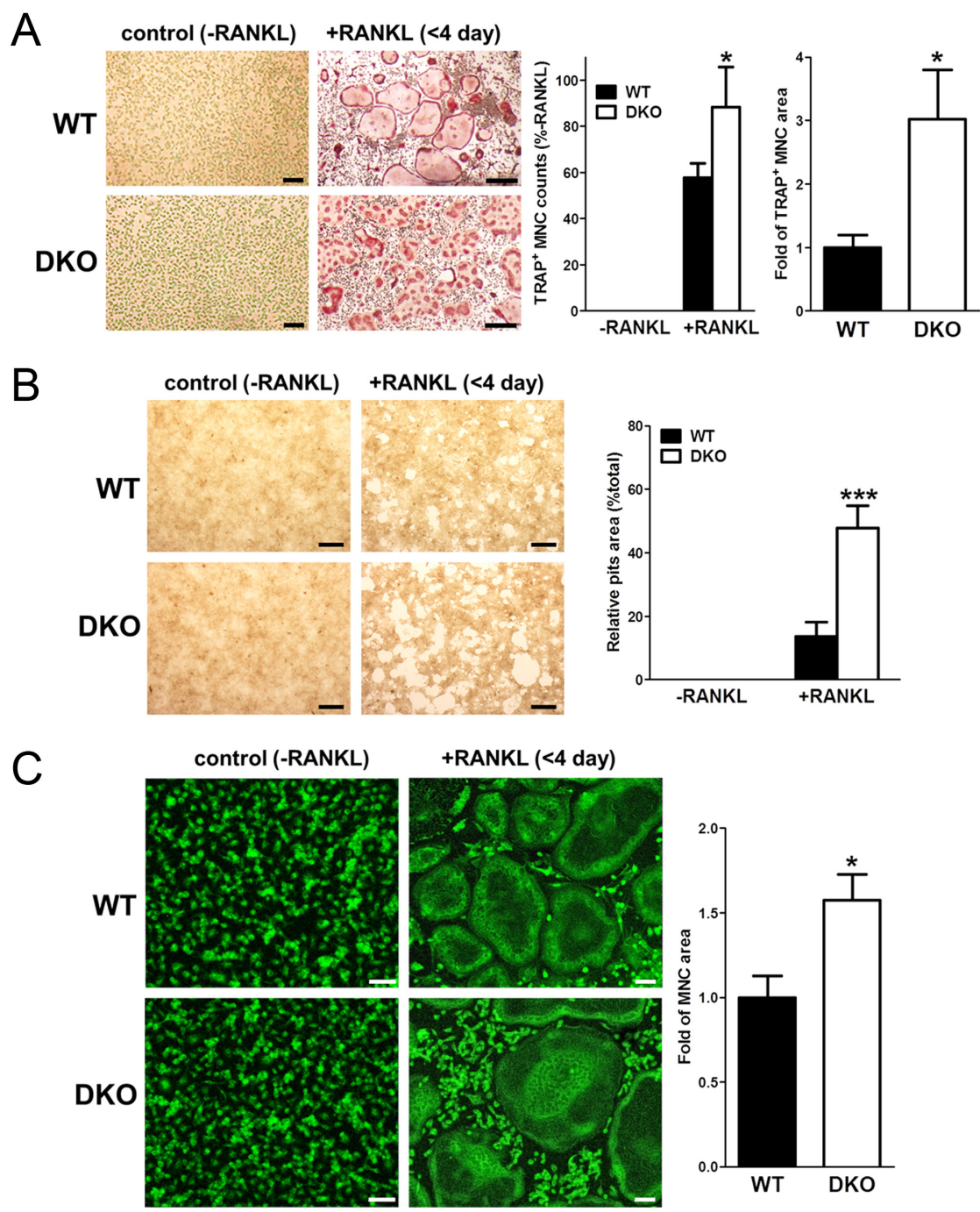

\section{Figure 4}

RANKL-induced osteoclastogenesis is enhanced in Homer2/3 DKO BMMs. (A) RANKL-induced osteoclast differentiation in vitro in WT and Homer2/3 DKO BMMs (TRAP staining; scale bar, $50 \mu \mathrm{m})$. Columns show quantitative analysis of the number (middle) and the area (right) of TRAPpositive (TRAP') multinucleated cells (MNCs; $\geq 3$ nuclei) in WT and Homer2/3 DKO mice. The number and area of TRAP + MNCs are significantly higher in Homer2/3 DKO mice $(n=4)$. (B) Pits area during osteoclastogenesis is higher in Homer2/3 DKO cells $(n=5)$. (C) Actin staining of TRAP ${ }^{+}$MNCs in WT and Homer2/3 DKO cells (scale bar, $20 \mu \mathrm{m}$ ). The area of actin ring formation in TRAP+ MNCs during osteoclastogenesis is significantly higher in Homer2/3 DKO cells $(n=6)$. We normalized the data to the number and area of MNCs in RANKL-treated BMMs of WT mice. Results were expressed as the mean \pm S.E.M. ${ }^{*} P<0.05$ and $* * * P<0.001$ compared with RANKL-treated WT. 
It has been shown that $\mathrm{Ca}^{2+}$ oscillations have a prominent role in osteoclastogenesis (Takayanagi et al. 2002, Yang et al. 2009, Kim et al. 2010). Furthermore, Homer proteins were reported to interact with several $\mathrm{Ca}^{2+}$ signaling proteins (Shin et al. 2003, Worley et al. 2007, Yang et al. 2014). However, we found that the increase in long-lasting $\left[\mathrm{Ca}^{2+}\right]_{\mathrm{i}}$ oscillations occurring between 24 and $72 \mathrm{~h}$ from RANKL stimulation (Fig. 2) occurred independently in Homer2/3 expressions. Therefore, it appears that Homer2 and Homer3 have another role in BMMs. Homer1 is the major regulator of $\mathrm{Ca}^{2+}$ signaling (Yuan et al. 2003), while Homer2 modulates only GPCR by affecting Gq-related signaling through RGS2 (Shin et al. 2003) and Homer3 has no known role in $\mathrm{Ca}^{2+}$ signaling. However, Homer2/3 competes with calcineurin for interaction with NFAT and may, therefore, regulate NFAT-dependent transcription (Huang et al. 2008). This accounts for the lack of effect of the DKO on RANKLmediated $\mathrm{Ca}^{2+}$ oscillations. Specifically, we believe that they regulate the NFATc1 system's function. As a consequence, the expression and translocation of NFATc1 appeared $12 \mathrm{~h}$ post RANKL treatment. Of note, these effects were enhanced in the RANKL-induced Homer2/3 DKO BMMs.

Previous reports showed that NFAT activation driving osteoclast differentiation requires NFAT expression's induction via NF- $\mathrm{BB}$ and $\mathrm{AP}-1$ and posttranslational activation induced by ITAM-associated immunoreceptors (Koga et al. 2004, Mocsai et al. 2004, Kuroda et al. 2008). Several studies suggest that NFAT binds Homer proteins participating in skeletal muscle differentiation and T cell activation (Stiber et al. 2005, Huang et al. 2008, Salanova et al. 2011). Huang and colleagues also reported that Homer2 and Homer3 play the action as a selective inhibitor to calcineurin-NFAT activation which the action was not related with AP1 and NF-kB pathway (Huang et al. 2008). Such mode of NFATc1 regulation appears to operate in both BMMs and osteoclasts. This is based on Homer proteins and NFATc1's interaction, which is dependent on calcineurin and markedly inhibited by RANKL stimulation during osteoclastogenesis (Fig. 3F). Therefore, our study shows that Homer proteins are necessary for the control of RANKL-mediated NFATc1 induction and translocation. Additionally, they represent key molecules of the NFATc1 signaling pathway and autoamplification during osteoclastogenesis. Accordingly, the deletion of Homer2/3 facilitated the formation of MNCs and bone resorption in late-stage osteoclastogenesis to reduced bone density.

In summary, these results provide strong evidence for the regulation of NFATc1 availability for transcriptional regulation by the Homers in osteoclasts and that the Homers are major regulators of osteoclasts differentiation and bone metabolism. Specifically, our findings indicate that Homer proteins constitute a node at which NFATc1 activity, formation of MNCs, and physiological activity of osteoclasts are sequentially regulated. We believe that our findings may have a clinical relevance in pathological conditions of the skeletal system. We demonstrated essential roles of Homer proteins in the RANKLinduced NFATc1 signaling pathway during osteoclasts differentiation. Such observations suggest a specific and potent therapeutic target for various bone diseases caused by the abnormal formation of osteoclasts.

\section{Declaration of interest}

The authors declare that there is no conflict of interest that could be perceived as prejudicing the impartiality of the research reported.

\section{Funding}

This work was supported by the National Research Foundation of Korea (NRF) grant funded by the Korea government MSIP (2016R1A5A2008630) and MOE (2012R1A1A2007673, 2015R1D1A1A01057277).

\section{Author contribution statement}

A S, Y M Y and D M S designed the study. A S, Y M Y, S Y O and N K performed experiments. A S and $Y M Y$ contributed to data acquisition and interpretation. $\mathrm{KW}$ K, Y M Y and D M S drafted and revised the manuscript. All authors approved the final version of the manuscript.

\section{Acknowledgement}

The authors thank Dr Paul F Worley for sharing the Homer2/3 DKO mice.

\section{References}

Berridge MJ, Bootman MD \& Roderick HL 2003 Calcium signalling: dynamics, homeostasis and remodelling. Nature Reviews: Molecular Cell Biology 4 517-529. (https://doi.org/10.1038/nrm1155)

Bootman MD, Lipp P \& Berridge MJ 2001 The organisation and functions of local Ca ${ }^{2+}$ signals. Journal of Cell Science $1142213-2222$.

Bottai D, Guzowski JF, Schwarz MK, Kang SH, Xiao B, Lanahan A, Worley PF \& Seeburg PH 2002 Synaptic activity-induced conversion of intronic to exonic sequence in Homer 1 immediate early gene expression. Journal of Neuroscience 22 167-175. (https://doi. org/10.1523/JNEUROSCI.22-01-00167.2002)

Brakeman PR, Lanahan AA, O'Brien R, Roche K, Barnes CA, Huganir RL \& Worley PF 1997 Homer: a protein that selectively binds metabotropic glutamate receptors. Nature 386 284-288. (https://doi. org/10.1038/386284a0)

Crabtree GR \& Olson EN 2002 NFAT signaling: choreographing the social lives of cells. Cell 109 (Supplement) S67-S79. (https://doi. org/10.1016/s0092-8674(02)00699-2)

Feng W, Tu J, Yang T, Vernon PS, Allen PD, Worley PF \& Pessah IN 2002 Homer regulates gain of ryanodine receptor type 1 channel complex. https://joe.bioscientifica.com https://doi.org/10.1530/JOE-19-0123 (c) 2019 Society for Endocrinology Published by Bioscientifica Ltd. Printed in Great Britain 
Journal of Biological Chemistry 277 44722-44730. (https://doi. org/10.1074/jbc.M207675200)

Foucault I, Le Bras S, Charvet C, Moon C, Altman A \& Deckert M 2005 The adaptor protein 3BP2 associates with VAV guanine nucleotide exchange factors to regulate NFAT activation by the B-cell antigen receptor. Blood 105 1106-1113. (https://doi.org/10.1182/blood-2003-08-2965)

GuezGuez A, Prod'homme V, Mouska X, Baudot A, Blin-Wakkach C, Rottapel R \& Deckert M 2010 3BP2 adapter protein is required for receptor activator of NFkappaB ligand (RANKL)-induced osteoclast differentiation of RAW264.7 cells. Journal of Biological Chemistry 285 20952-20963. (https://doi.org/10.1074/jbc.M109.091124)

Hogan PG, Chen L, Nardone J \& Rao A 2003 Transcriptional regulation by calcium, calcineurin, and NFAT. Genes and Development $\mathbf{1 7}$ 2205-2232. (https://doi.org/10.1101/gad.1102703)

Huang GN, Huso DL, Bouyain S, Tu J, McCorkell KA, May MJ, Zhu Y, Lutz M, Collins S, Dehoff M, et al. 2008 NFAT binding and regulation of $\mathrm{T}$ cell activation by the cytoplasmic scaffolding Homer proteins. Science 319 476-481. (https://doi.org/10.1126/science.1151227)

Kim MS, Yang YM, Son A, Tian YS, Lee SI, Kang SW, Muallem S \& Shin DM 2010 RANKL-mediated reactive oxygen species pathway that induces long lasting $\mathrm{Ca}^{2+}$ oscillations essential for osteoclastogenesis. Journal of Biological Chemistry 285 6913-6921. (https://doi. org/10.1074/jbc.M109.051557)

Koga T, Inui M, Inoue K, Kim S, Suematsu A, Kobayashi E, Iwata T, Ohnishi H, Matozaki T, Kodama T, et al. 2004 Costimulatory signals mediated by the ITAM motif cooperate with RANKL for bone homeostasis. Nature 428 758-763. (https://doi.org/10.1038/nature02444)

Kuroda Y, Hisatsune C, Nakamura T, Matsuo K \& Mikoshiba K 2008 Osteoblasts induce $\mathrm{Ca}^{2+}$ oscillation-independent NFATc1 activation during osteoclastogenesis. PNAS 105 8643-8648. (https://doi. org/10.1073/pnas.0800642105)

Mayingi J, Helary G, Noirclere F, Bacroix B \& Migonney V 2007 Grafting of bioactive polymers onto titanium surfaces and human osteoblasts response. Conference Proceedings Annual International Conference of the IEEE Engineering in Medicine and Biology Society 2007 5119-5122. (https://doi.org/10.1109/IEMBS.2007.4353492)

Mizutani A, Kuroda Y, Futatsugi A, Furuichi T \& Mikoshiba K 2008 Phosphorylation of Homer3 by calcium/calmodulin-dependent kinase II regulates a coupling state of its target molecules in Purkinje cells. Journal of Neuroscience $\mathbf{2 8}$ 5369-5382. (https://doi.org/10.1523/ JNEUROSCI.4738-07.2008)

Mocsai A, Humphrey MB, Van Ziffle JA, Hu Y, Burghardt A, Spusta SC, Majumdar S, Lanier LL, Lowell CA \& Nakamura MC 2004 The immunomodulatory adapter proteins DAP12 and Fc receptor gammachain (FcRgamma) regulate development of functional osteoclasts through the Syk tyrosine kinase. PNAS 101 6158-6163. (https://doi org/10.1073/pnas.0401602101)

Olson EN \& Williams RS 2000 Calcineurin signaling and muscle remodeling. Cell 101 689-692. (https://doi.org/10.1016/s00928674(00)80880-6)

Park B, Yang YM, Choi BJ, Kim MS \& Shin DM 2013 Activation of $\mathrm{G}$ proteins by aluminum fluoride enhances RANKL-mediated osteoclastogenesis. Korean Journal of Physiology and Pharmacology 17 427-433. (https://doi.org/10.4196/kjpp.2013.17.5.427)

Salanova M, Bortoloso E, Schiffl G, Gutsmann M, Belavy DL, Felsenberg D, Furlan S, Volpe P \& Blottner D 2011 Expression and regulation of Homer in human skeletal muscle during neuromuscular junction adaptation to disuse and exercise. FASEB Journal $\mathbf{2 5}$ 4312-4325. (https://doi.org/10.1096/fj.11-186049)

Shanmugarajan S, Haycraft CJ, Reddy SV \& Ries WL 2012 NIP45 negatively regulates RANK ligand induced osteoclast differentiation.
Journal of Cellular Biochemistry 113 1274-1281. (https://doi. org/10.1002/jcb.23460)

Shin DM, Dehoff M, Luo X, Kang SH, Tu J, Nayak SK, Ross EM, Worley PF \& Muallem S 2003 Homer 2 tunes G protein-coupled receptors stimulus intensity by regulating RGS proteins and PLCbeta GAP activities. Journal of Cell Biology 162 293-303. (https://doi. org/10.1083/jcb.200210109)

Son A, Kim MS, Jo H, Byun HM \& Shin DM 2012 Effects of inositol 1,4,5-triphosphate on osteoclast differentiation in RANKL-induced osteoclastogenesis. Korean Journal of Physiology and Pharmacology 16 31-36. (https://doi.org/10.4196/kjpp.2012.16.1.31)

Stiber JA, Tabatabaei N, Hawkins AF, Hawke T, Worley PF, Williams RS \& Rosenberg P 2005 Homer modulates NFAT-dependent signaling during muscle differentiation. Developmental Biology 287 213-224. (https://doi.org/10.1016/j.ydbio.2005.06.030)

Takayanagi H 2007 The role of NFAT in osteoclast formation. Annals of the New York Academy of Sciences 1116 227-237. (https://doi. org/10.1196/annals.1402.071)

Takayanagi H, Kim S, Koga T, Nishina H, Isshiki M, Yoshida H, Saiura A, Isobe $\mathrm{M}$, Yokochi T, Inoue J, et al. 2002 Induction and activation of the transcription factor NFATc1 (NFAT2) integrate RANKL signaling in terminal differentiation of osteoclasts. Developmental Cell 3 889-901. (https://doi.org/10.1016/S1534-5807(02)00369-6)

Tu JC, Xiao B, Yuan JP, Lanahan AA, Leoffert K, Li M, Linden DJ \& Worley PF 1998 Homer binds a novel proline-rich motif and links group 1 metabotropic glutamate receptors with $\mathrm{IP}_{3}$ receptors. Neuron 21 717-726. (https://doi.org/10.1016/S0896-6273(00)80589-9)

Tu JC, Xiao B, Naisbitt S, Yuan JP, Petralia RS, Brakeman P, Doan A, Aakalu VK, Lanahan AA, Sheng M, et al. 1999 Coupling of mGluR/ Homer and PSD-95 complexes by the Shank family of postsynaptic density proteins. Neuron 23 583-592. (https://doi.org/10.1016/S08966273(00)80810-7)

Worley PF, Zeng W, Huang G, Kim JY, Shin DM, Kim MS, Yuan JP, Kiselyov K \& Muallem S 2007 Homer proteins in $\mathrm{Ca}^{2+}$ signaling by excitable and non-excitable cells. Cell Calcium 42 363-371. (https:// doi.org/10.1016/j.ceca.2007.05.007)

Xiao B, Tu JC, Petralia RS, Yuan JP, Doan A, Breder CD, Ruggiero A, Lanahan AA, Wenthold RJ \& Worley PF 1998 Homer regulates the association of group 1 metabotropic glutamate receptors with multivalent complexes of homer-related, synaptic proteins. Neuron 21 707-716. (https://doi.org/10.1016/S0896-6273(00)80588-7)

Yang YM, Kim MS, Son A, Hong JH, Kim KH, Seo JT, Lee SI \& Shin DM 2009 Alteration of RANKL-induced osteoclastogenesis in primary cultured osteoclasts from SERCA2+/- mice. Journal of Bone and Mineral Research 24 1763-1769. (https://doi.org/10.1359/jbmr.090420)

Yang YM, Jung HH, Lee SJ, Choi HJ, Kim MS \& Shin DM 2013 TRPM7 is essential for RANKL-induced osteoclastogenesis. Korean Journal of Physiology and Pharmacology 17 65-71. (https://doi.org/10.4196/ kjpp.2013.17.1.65)

Yang YM, Lee J, Jo H, Park S, Chang I, Muallem S \& Shin DM 2014 Homer2 protein regulates plasma membrane $\mathrm{Ca}^{2+}$-ATPase-mediated $\mathrm{Ca}^{2+}$ signaling in mouse parotid gland acinar cells. Journal of Biological Chemistry 289 24971-24979. (https://doi.org/10.1074/jbc. M114.577221)

Yuan JP, Kiselyov K, Shin DM, Chen J, Shcheynikov N, Kang SH, Dehoff MH, Schwarz MK, Seeburg PH, Muallem S, et al. 2003 Homer binds TRPC family channels and is required for gating of TRPC1 by $\mathrm{IP}_{3}$ receptors. Cell 114 777-789. (https://doi.org/10.1016/s00928674(03)00716-5)

Zaidi M 2007 Skeletal remodeling in health and disease. Nature Medicine 13 791-801. (https://doi.org/10.1038/nm1593)

Received in final form 19 June 2019

Accepted 18 July 2019

Accepted Preprint published online 18 July 2019 https://joe.bioscientifica.com https://doi.org/10.1530/JOE-19-0123 (c) 2019 Society for Endocrinology Published by Bioscientifica Ltd. Printed in Great Britain 